\title{
Overexpression of cortactin increases invasion potential in oral squamous
}

\section{cell carcinoma}

Shin-ichi Yamada, DDS, $\mathrm{PhD}^{1}$; Souichi Yanamoto, $\mathrm{DDS}, \mathrm{PhD}^{1}$; Goro Kawasaki, $\mathrm{DDS}, \mathrm{PhD}^{1}$; Akio

Mizuno, DDS, $\mathbf{P h D}^{1}$; and Takayuki K. Nemoto, $\mathbf{P h D}^{2}$

${ }^{1}$ Department of Oral and Maxillofacial Surgery, Unit of Translational Medicine, Course of Medical and

Dental Sciences, Nagasaki University Graduate School of Biomedical Sciences.

${ }^{2}$ Department of Oral Molecular Biology, Unit of Basic Medical Sciences, Course of Medical and Dental

Sciences, Nagasaki University Graduate School of Biomedical Sciences.

Key Words: cortactin, invasion, metastasis, RNA interference, oral squamous cell carcinoma 
Running title: Overexpression of cortactin in oral squamous cell carcinoma

Abbreviations: : (OSCC) oral squamous cell carcinoma, (EGF)epidermal growth factor,

(EGFR)epidermal growth factor receptor, (PTHrP)parathyroid hormone- related protein

Correspondence: Shin-ichi Yamada, DDS, PhD

Department of Oral and Maxillofacial Surgery, Unit of Translational Medicine, Course of Medical and

Dental Sciences, Nagasaki University Graduate School of Biomedical Sciences.

1-7-1 Sakamoto, Nagasaki 852-8588, Japan

Email: shinshin@nagasaki-u.ac.jp

Fax: + 8195 8197700, Tel: + 81958197698 


\section{Abstract}

Cortactin, an F-actin binding protein, stabilizes F-actin networks and promotes actin polymerization by

activating the Arp2/3 complex. Overexpression of cortactin has been reported in several human cancers.

Cortactin stimulates cell migration, invasion, and experimental metastasis. However, the underlying

mechanism is not still understood. In the present study, we therefore evaluated the possibility that cortactin

could be appropriate as a molecular target for cancer gene therapy. In 70 primary oral squamous cell

carcinomas and 10 normal oral mucosal specimens, cortactin expression was evaluated by immunological

analyses, and the correlations of the overexpression of cortactin with clinicopathologic factors were

evaluated. Overexpression of cortactin was detected in 32 of 70 oral squamous cell carcinomas;

significantly more frequently than in normal oral mucosa. Cortactin overexpression was more frequent in

higher grade cancers according to T classification, $\mathrm{N}$ classifications, and invasive pattern. Moreover,

RNAi-mediated decrease in cortactin expression reduced invasion. Downregulation of cortactin expression 
increased the expression levels of E-cadherin, $\beta$-catenin, and EpCAM. The siRNA of cortactin also reduced

PTHrP expression via EGF signaling. These results consistently indicate that the overexpression of

cortactin is strongly associated with an aggressive phenotype of oral squamous cell carcinoma. In

conclusion, we propose that cortactin could be a potential molecular target of gene therapy by RNAi

targeting in oral squamous cell carcinoma. 


\section{Introduction}

Oral squamous cell carcinoma (OSCC) is the most common malignant tumor of the head and neck

region and accounts for more than $90 \%$ of cancers of the oral cavity. ${ }^{1}$ The primary therapeutic modality for

OSCC is surgery. Although recent advances in surgical techniques and anticancer agents have improved

tumor regression and survival for patients with OSCC, wide surgical resection of OSCC causes various oral

dysfunctions. Therefore, new treatment strategies are urgently needed.

The presence of neck lymph node metastasis is strongly related to a poor prognosis in squamous cell

carcinoma of the head and neck..$^{2-4}$ Moreover, alterations in the expression of adhesion-related molecules

are reported to be associated with poor prognosis among OSCC patients. ${ }^{5-8}$

Gene amplification, leading to an increase of DNA copy numbers and overexpression of oncogenes in

many tumors, is reported to contribute to the growth advantage of cells, subsequently changing their

biological behaviors, and causing carcinogenesis. ${ }^{9-11}$ Chromosomal band $11 \mathrm{q} 13$ is a frequently amplified 
genomic segment in a large number of malignant neoplasms, and is thought of as a potential biomarker for

diagnosis and prognosis ${ }^{12,13}$.In head and neck squamous cell carcinoma, this amplification is one of the

most frequently observed genetic alterations ${ }^{14-23}$ and is reportedly correlated with aggressive tumor

growth, ${ }^{12,16,22}$ the presence of lymph node metastases, ${ }^{20,24-26}$ and poor prognosis. ${ }^{12,22,27}$ The amplified

$11 \mathrm{q} 13$ region is 3-5 megabases in size and includes four putative oncogenes: CCND1 (PRAD1), FGF3

(INT2), FGF4 (HST1), and EMS1. Because CCND1 and EMS1 were found to be overexpressed in all

carcinomas carrying the $11 \mathrm{q} 13$ amplification, they are believed to be the more important candidate

oncogenes. ${ }^{13}$

Cortactin, which is encoded by the EMS1 gene, is amplified in 30\% of head and neck squamous cell

carcinomas and $13 \%$ of primary breast cancers. ${ }^{16,28-31}$ Cortactin is an actin-associated scaffolding protein

that binds and activates the actin-related protein (Arp) 2/3 complex, and regulates branched actin networks

in the formation of dynamic cortical actin-associated structures. ${ }^{32,33}$ Amplification of the EMS1 gene and 
the overexpression of cortactin have been reported in breast cancer, bladder cancer, hepatocellular

carcinoma, esophageal carcinoma, and head and neck squamous cell carcinoma. ${ }^{22,23,27,34-38}$ Cortactin

overexpression has been postulated to mediate the increased invasive and metastatic behaviors of tumor

cells because of its effects in the organization and the functioning of cytoskeleton and cell adhesion

structures. ${ }^{37}$ However, the relationship between cortactin expression and invasiveness and metastatic

potential remain unknown for OSCC. In this study, we initially immunohistochemically examined cortactin

expression in OSCC. We then determined the clinicopathological significance of cortactin expression in

relation to various parameters such as patient characteristics and histopathological findings. Moreover,

siRNA analysis was also performed to assess whether cortactin could be a potent molecular target for

cancer gene therapy in OSCC. 


\section{Materials and methods}

Patients

Paraffin-embedded sections were obtained from biopsy specimens of 70 patients with OSCC who

underwent radical surgery in our department. Tumor stage was classified according to the TNM

classification of the International Union Against Cancer, histological differentiation was defined according

to the WHO classification, and invasion pattern was determined according to Bryne's classification. ${ }^{22}$ As

controls, samples of normal oral epithelium were obtained after informed consent from ten patients

undergoing routine surgical removal of their third molars.

Cell lines

SAS, a human OSCC cell line, was obtained from the Human Science Research Resource Bank (Osaka,

Japan). The cells were cultured under conditions recommended by their depositors. 
Immunohistochemical staining and evaluation

Serial $4-\mu \mathrm{m}$ thick specimens were taken from tissue blocks. Sections were deparaffinized in xylene,

soaked in target retrieval solution buffer (Dako, Glostrup, Denmark) and placed in an autoclave at $121^{\circ} \mathrm{C}$

for 5 min for antigen retrieval. Endogenous peroxidase was blocked by incubation with $0.3 \% \mathrm{H}_{2} \mathrm{O}_{2}$ in

methanol for 30 min. Immunohistochemical staining was performed using the Envision system (Envision+,

Dako, Carpinteria, CA). The primary antibody used was directed against cortactin (4D10, Abnova, Taipei,

Taiwan). The sections were incubated with the monoclonal antibody overnight at $4^{\circ} \mathrm{C}$. Reaction products

were visualized by immersing the sections in diaminobenzidine (DAB) solution, and the samples were

counterstained with Meyer's hematoxylin and mounted. Negative controls were performed by replacing the

primary antibody with phosphate-buffered saline. Cortactin expression was defined as the presence of

specific staining in the cytoplasm and cytoplasm membrane of tumor cells. The immunoreactivity of 
cortactin was scored by staining intensity and immunoreactive cell percentage as follows ${ }^{37}$ : staining index 0

$=$ tissue with no staining; $1=$ tissue with faint or moderate staining in $25 \%$ of tumor cells; $2=$ tissue with moderate or strong staining in $25 \%$ to $50 \%$ of tumor cells; $3=$ tissue with strong staining in $50 \%$ of tumor cells. Overexpression of cortactin was defined as staining index 2.

RNA isolation and semiquantitative reverse transcription-polymerase chain reaction (RT-PCR)

Total RNA was isolated with TRIzol Reagent (Invitrogen, Carlsbad, CA) and first-strand cDNA was

synthesized from $1 \mu \mathrm{g}$ total RNA using Oligo d (T) primer (Invitrogen) and ReverTra Ace (Toyobo, Osaka, Japan). For PCR analysis, cDNA was amplified by Taq DNA polymerase (Takara, Otsu, Japan).

Glyceraldehyde-3-phosphate dehydrogenase (GAPDH) was used as the endogenous expression standard.

Each PCR program involved a 3-min initial denaturation step at $94^{\circ} \mathrm{C}$, followed by 23 cycles (for cortactin),

or 18 cycles (for GAPDH) at $94^{\circ} \mathrm{C}$ for $30 \mathrm{~s}, 55^{\circ} \mathrm{C}$ for $30 \mathrm{~s}$, and $72^{\circ} \mathrm{C}$ for $1 \mathrm{~min}$, on a PCR Thermal Cycler 
MP (Takara). Primer sequences were as follows: TGGGGAGGGGAATATACACA for cortactin (F);

CTCTAGAGGAAGCCCCTCGT for cortactin (R); GCCCCATTCGTTCAAGTAGTCA for E-cadherin

(F) ; TTCCGAAGCTGCTAGTCTGAGC for E-cadherin (R), TGGCCTGGTTTGATACTGACCT

for $\beta$-catenin (F); CTCTACAGGCCAATCACAATGC for $\beta$-catenin (R); CCAGAACAATGATGGGCTTT

for EpCAM (F); ACGCGTTGTGATCTCCTTCT for EpCAM (R); GGTGGCACCAAAGCTGTATT for

FGFR (F); GGTGCAGGAGAGGAGAACTG for EGFR (R); ACAGTTGGAGTAGCCGGTTG for PTHrP

(F); TCAGCTGTGTGGATTTCTGC for PTHrP (R); ATGTCGTGGAGTCTACTGGC for GAPDH (F);

and TGACCTTGCCCACAGCCTTG for GAPDH (R). The amplified products were separated by

electrophoresis on ethidium bromide-stained 2\% agarose gels. Band intensity was quantified by Image J

software.

Invasion assay 
A BioCoat Matrigel invasion chamber (Becton Dickinson, Bedford, MA) was used for the invasion assay. This contains an internal chamber with an $8-\mu \mathrm{m}$ porous membrane bottom that was coated with Matrigel. Six-well cell culture inserts and a 6-well multiwell companion plate were used for the experiment.

The membranes were rehydrated with warm serum-free medium for $2 \mathrm{~h}$. The internal chamber was filled

with $1.25 \times 10^{5}$ cells in medium containing $10 \%$ FBS as a chemoattractant. Cells were incubated for $72 \mathrm{~h}$ at $37^{\circ} \mathrm{C}$ in a $5 \% \mathrm{CO}_{2}$ atmosphere. After the incubation, noninvading cells were removed from the top of the wells with a cotton swab, and cells that transferred to the inverse surface of the membrane were subjected to Diff-Quick staining. Cells were counted under a microscope at $100 \times$ magnification. For the control cell count, cells that passed through a control chamber without Matrigel were counted. All experiments were performed in triplicate, and cell numbers at least in 4 fields/well were counted. The ratio of the cell count that passed through the Matrigel chamber to the control cell count was defined as the invasion index, expressed as a percentage. 
RNA interference (RNAi)

All siRNAs were purchased from Takara Bio Inc. (Otsu, Japan). Cells were transfected with

double-strand RNA using TransIT-siQUEST ${ }^{\circledR}$ transfection reagent (Mirus, Madison, USA) according to the

manufacturer's protocol. The SAS tongue cancer cell line was used for this experiment. Briefly, $1.0 \times 10^{5}$

SAS cells were plated in each well of six-well plates and allowed to grow for $24 \mathrm{~h}$, till they reached $50 \%$

confluence. Cells were then transfected with siRNA at a concentration of $200 \mathrm{nM}$ using the transfection

reagent and serum-free medium. Following $24 \mathrm{~h}$ of incubation, serum-rich medium was added. The EMS1

siRNA sequences were 5'-CAAGACCGAAUGGAUAAGUTT-3' and

5'-ACUUAUCCAUUCGGUCUUGTT-3'. The scrambled control siRNA sequences were

5'-CGUAUGCGCGUACUCUAAUTT-3' and 5'-TTGCAUACGCGCAUGAGAUUA-3'. All sequences

were submitted to the National Institutes of Health Blast program to ensure gene specificity. 
Western blot analysis

Cells were harvested by trypsinization, washed, and precipitated by centrifugation. The Mammalian

Cell Extraction Kit (BioVision Research Products, Mountain View, CA) was used for the extraction of

proteins. All subsequent manipulations were performed on ice. The cells were incubated in the Extraction

Buffer Mix. The lysed cells were centrifuged at 15,000 rpm for $3 \mathrm{~min}$ and the supernatant was collected as

the cytoplasmic fraction. Protein concentration of each sample was measured with micro-BCA protein

assay reagent (Pierce Chemical Co.). Samples were denatured in SDS sample buffer and loaded onto

$12.5 \%$ polyacrylamide gels. After electrophoresis, the proteins were transferred onto a polyvinylidine

difluoride membrane and immunoblotted with anti-cortactin (H-191, Sanra Cruz, California, USA),

anti-E-cadherin (Cell Signaling, MA, USA), anti- $\beta$-actin (Cell Signaling, MA, USA),

anti-EpCAM(HEA-125, Gene Tax, San Antonio, TX), or anti-EGFR(H11,Thermo, Cheshire, UK). Signals 
were detected using a horseradish peroxidase-conjugated secondary antibody (ECL antimouse IgG,

Amersham Biosciences, Piscataway, NJ; $0.01 \mu \mathrm{g} / \mathrm{ml}$ ), and then visualized using an ECL Kit (Amersham

Pharmacia Biotech, Buckinghamshire, UK).

Statistical analysis

Statistical analysis was performed using StatMate ${ }^{\circledR}$ (ATMS Co., Tokyo, Japan). The associations between cortactin expression and clinicopathologic features were assessed by Fischer's exact test. To determine significant prognostic factors related to survival, multivariate analysis was performed using the Cox proportional hazards regression model. Continuous data are given as mean \pm standard deviation. Data sets were examined by one-way analysis of variance (ANOVA) followed by Scheffe's post-hoc test. The correlation between cortactin mRNA expression and invasion index was determined using Person's correlation coefficient. $\mathrm{P}$ values less than 0.05 were considered significant. 


\section{Results}

\section{Correlation between cortactin overexpression and clinicopathologic features}

Immunohistochemistry with an anti-cortactin-specific monoclonal antibody was performed on a series

of 70 patients with oral squamous cell carcinoma. Representative immunohistochemical stainings are

shown in Figure 1. Overexpression of cortactin was undetectable in the normal epithelium (Fig. 1A). In the

squamous cell carcinoma cells, strong cortactin staining was apparent at the invasive front and the diffuse

invasive area. Cortactin overexpression was detected significantly more frequently in OSCC (32 of 70,

$45.7 \%)$ than in normal oral epithelium ( 0 of $10,0 \% ; \mathrm{p}<0.01)$. Moreover, cortactin overexpression was

significantly more frequent in cancers with higher grade according to T classification (T 3/4 vs. 1/2;

$\mathrm{p}<0.001$ ), $\mathrm{N}$ classification (N 3/4 vs. $1 / 2 ; \mathrm{p}<0.05$ ), or invasive pattern (grade $3 / 4$ vs. $1 / 2 ; \mathrm{p}<0.001$, Table 1 ).

Cox regression analysis was performed with the parameters of histologic differentiation $(\mathrm{T}$

classification, $\mathrm{N}$ classification, and pattern of invasion) and cortactin overexpression. Cox regression 
analysis revealed a correlation between $\mathrm{N}$ classification (hazard ratio: 3.71, 95\% CI: 0.420-2.20, P: 0.004),

pattern of invasion (hazard ratio: 2.65, 95\% CI: 0.055-1.89, P: 0.038), and cortactin overexpression (hazard

ratio: $2.80,95 \%$ CI: $0.091-1.97$, P: 0.032 , Table 2). These findings strongly suggested that cortactin

overexpression would be a significant independent predictor of survival.

Effect of decreasing cortactin expression on the invasion potential of SAS cells

To determine the effect of decreasing cortactin expression on invasion potential, we transfected

SAS cells with cortactin siRNA (Fig. 2A,B) and performed the Matrigel invasion assay. Transfection with

cortactin siRNA significantly decreased the mRNA and protein levels of cortactin, compared with those in

non-transfected cells and cells transfected with scrambled siRNA (Fig.2A, B). Concomitantly, the invasion

index of the SAS cells decreased significantly from $13.2 \%$ (in cells treated with vehicle alone) and $12.4 \%$

(in cells transfected with scrambled siRNA) to $0.02 \%$ in cells transfected with cortactin siRNA (Fig. 2C). 
Furthermore, the mRNA expressions of E-cadherin, $\beta$-catenin and EpCAM were significantly decreased in cortactin-targeted siRNA transfected SAS cells (Fig. 3A). A very similar tendency was seen in the protein levels, with the exception of $\beta$-catenin (Fig. 3B). Therefore, downregulation of cortactin expression by siRNA drastically suppressed the mobility of SAS cells in vitro.

Effect of decreasing cortactin expression on PTHrP expression via the EGFR signaling pathway

PTHrP was firstly discovered as a causative protein for hypercalcemia, which is frequently

encountered during the terminal phase of malignant tumors. ${ }^{39,40}$ PTHrP contributes to the malignancy of

oral cancers downstream of EGFR signaling. ${ }^{41}$ We therefore examined the effect of decreasing cortactin expression on PTHrP expression via the EGFR signaling pathway. Cortactin-targeted siRNA transfection of SAS cells significantly decreased EGFR and PTHrP gene expressions (Fig. 3A). In terms of protein level, EGFR expression was decreased by the cortactin-targeted siRNA transfection (Fig. 3B). These results 
suggest that cortactin also may act as a mediator of EGFR signaling, as well as PTHrP, in OSCC. 


\section{Discussion}

Cortactin has been described as an actin associated scaffolding protein. It binds and activates the Arp

$2 / 3$ complex and regulates the branched actin networks in the formation of dynamic cortical

actin-associated structures. ${ }^{32,33}$ Cortactin is also thought to relate to functions involving membrane

dynamics and cortical actin assembly, including cell migration, morphogenesis, adhesion,

receptor-mediated endocytosis, and pathogen invasion to improve the connection with the list of

functions ${ }^{42}$ The amplification of cortactin has been reported in $30 \%$ of head and neck squamous cell

carcinomas and $13 \%$ of primary breast cancers. ${ }^{16,28-31}$ In head and neck squamous cell carcinoma, the

amplification of cortactin correlates with poor prognosis. ${ }^{21}$ In nude mice with esophageal squamous cell

carcinoma, tail vein injection of cortactin siRNA-transfected cells decreased lung metastasis and prolonged

survival time compared with controls. ${ }^{37}$ In addition, in the same animal model, amplification and

overexpression of cortactin contribute to metastasis, anoikis resisitance, ${ }^{37}$ and carcinogesis. ${ }^{38}$ In NIH3T3 
fibroblasts, overexpression of EMS1/cortactin increases cell motility and invasion in vitro. ${ }^{43}$ Enhancement

of migration ability facilitates tumor invasion, which is the principal mechanism reported to account for the

role of cortactin in tumor metastasis. ${ }^{33}$ The ectopic expression of cortactin potentiates bone metastasis of

breast cancer by increasing the adhesive affinity of tumor cells for bone marrow endothelial cells. ${ }^{44}$

Therefore, the overexpression of cortactin endows cancer cells with various capabilities for metastasis.

In previous studies, cortactin overexpression has reported to be correlated with carcinogenesis, ${ }^{38}$ lymph

node metastasis, ${ }^{37}$ and poor prognosis. ${ }^{21}$ In this study, cortactin overexpression was strongly correlated with

cancers of higher grade according to T classification, $\mathrm{N}$ classification, and invasive pattern. Additionally,

Cox regression analysis revealed a correlation between $\mathrm{N}$ classification, pattern of invasion, and cortactin

overexpression, respectively. We demonstrated that cortactin overexpression in OSCC could reflect a large

tumor size, regional lymph node metastasis, and diffuse invasion. Moreover, it was suggested that cortactin

expression could be a prognostic factor in OSCC patients. 
The present study also demonstrated that cortactin expression could be associated with invasiveness in the human tongue squamous cell carcinoma cell line, SAS. Our study indicated that the de novo overexpression of cortactin increased the invasion potential of tongue squamous cell carcinoma cells.

Moreover, the immunohistochemical staining of cortactin revealed strong positivity in the invasive front of the diffuse invasion pattern. However, the mechanism by which cortactin increases the invasive potential remains unclear.

There is a correlation between the ability of cells to locally degrade the matrix at invadopodia, which are actin-containing protrusions extending into the matrix and participating in matrix degradation, and their invasive potential as measured in other in vivo and in vitro assays for motility and invasion. ${ }^{45}$ Cortactin binds to F-actin in vitro, colocalizing with cortical actin at ruffling membranes, and possesses actin-bundling activity that is modulated by c-Src, suggesting a role in membrane motility. ${ }^{46,47}$ Cortactin is reportedly recruited to cell-cell adhesive contacts in response to homophilic cadherin ligation. ${ }^{48}$ Moreover, 
one of the molecular mechanisms that links cadherins and actin assembly is likely to involve the interaction

between E-cadherin and the Arp2/3 actin nucleator complex. ${ }^{48}$ Cadherin adhesive ligation can recruit the

Arp2/3 complex to the cell surface ${ }^{49}$, and cortactin can interact with Arp2/3 (via an $\mathrm{NH}_{2}$-terminal acidic

[NTA] domain) and F-actin (via the fourth of six tandem repeats located in the $\mathrm{NH}_{2}$-terminal half of the

molecule $)^{50}$. In contrast, cortactin inhibits the disassembly of Arp2/3-generated actin filaments, and

potentially stabilizes the cortical actin network. ${ }^{51}$ Cortactin activity is necessary for the Arp2/3-dependent

actin assembly that occurs in response to E-cadherin homophilic ligation. ${ }^{48}$

Colocalization and association of cortactin with E-cadherin have been reported in epithelial cells. ${ }^{48}$ In

previous reports, reduction of cortactin expression levels had no effect on E-cadherin or $\beta$-catenin

levels. ${ }^{48,52}$ However, RNAi-mediated downregulation of cortactin resulted in significant reduction of

intercellular adhesion. ${ }^{52}$ Additionally, cortactin downregulation delayed the formation of early nascent

E-cadherin-based-cell-cell contacts. ${ }^{48}$ Catenin links cadherin with the actin cytoskeleton, and can also form 
a complex with EGFR. ${ }^{53}$ It was reported that EpCAM expression could be associated with invasiveness in human tongue cancer cell lines. ${ }^{8}$ The EpCAM overexpression decreased adhesion mediated by the cadherin-catenin complex. ${ }^{54,55}$ In this study, siRNA of cortactin resulted in the downregulation of adhesion molecules such as E-cadherin, $\beta$-batenin, and EpCAM levels, in contrast to previous reports. ${ }^{48,52}$ It is suggested that cortactin expression might also affect expression levels of these molecules and thereby contribute to invasive ability in OSCC cells.

Epidermal growth factor (EGF) is enriched in the oral region, and most OSCC cells express abundant EGF receptor(EGFR). ${ }^{56}$ The increased expressions of EGFR or its ligand are associated with reduced disease-free survival. ${ }^{57}$ The overexpression of cortactin in head and neck squamous cell carcinoma cells attenuates ligand-induced downregulation of the EGFR, which leads to sustained receptor signaling to the mitogenic extracellular signal-regulated kinase (ERK)/ mitogen-activated protein kinase pathway (MAPK) ${ }^{58} \mathrm{PTHrP}$ was first reported as a major factor responsible for hypercalcemia in malignancies, ${ }^{59}$ and 
acts classically as a stimulator of osteoclastic bone resorption. ${ }^{60}$ EGF signaling up-regulates PTHrP gene expression through the MAPK cascades, leading to malignant conversion of OSCC by enhanced cell proliferation, migration, and invasion. ${ }^{41}$ EGF activated ERK, p38 MAPK, and JNK in OSCC, and in particular, ERK and p38 MAPK were involved in PTHrP expression. ${ }^{41}$ In this report, we examined the effect of cortactin expression on the PTHrP expression via EGF signaling by the siRNA downregulation of cortactin. Cortactin down-regulation reduced EGFR and PTHrP mRNA expression levels. It is suggested that cortactin expression might contribute to PTHrP expression via EGF signaling and accordingly enhance cell proliferation and invasiveness of OSCC.

In summary, we showed the significance of cortactin expression as a potential prognostic factor of OSCC and the possibility of an association between cortactin and PTHrP expression via EGF signaling. RNAi technology is a specific and powerful tool to turn off the expression of oncogenic target genes. ${ }^{61}$ In oral cancer, the possibility of RNA-mediated gene therapy has been reported. ${ }^{62,63}$ We successfully applied 
RNA silencing to inhibit the expression of cortactin, thereby decreasing the invasion potential of OSCC.

Therefore, we propose that RNAi-mediated gene silencing of cortactin might be a useful modality for

OSCC treatment in the future.

\section{Acknowledgements}

We would like to thank Prof. Tohru Ikeda and Associate Prof. Shuichi Fujita of the Department of

Oral Pathology and Bone Metabolism, Unit of Basic Medical Sciences, Course of Medical and Dental

Sciences, Nagasaki University Graduate School of Biomedical Sciences for their help in preparing this

manuscript. 
This study was supported in part by Grant 18791508 from the Ministry of Education, Culture, Sports,

Science and Technology, Japan.

Funding: None

Competing interests: None declared

Ethical approval: Not require 


\section{Reference}

1. Mao L, Hong WK, Papadimitrakopoulou VA. (2004) Focus on head and neck cancer. Cancer Cell

$5: 311-316$

2. Hicks WL Jr, North JH Jr, Loree TR, et al. (1998) Surgery as a single modality therapy for squamous

cell carcinoma of the oral tongue. Am J Otolaryngol 19:24-28.

3. Sessions DG, Lenox J, Spector GJ, et al. (2003) Analysis of treatment results for base of tongue cancer.

Laryngoscope 113:1252-1261.

4. González-García R, Naval-Gías L, Rodríguez-Campo FJ, et al. (2008) Contralateral lymph neck node

metastasis of squamous cell carcinoma of the oral cavity: a retrospective analytic study in 315 patients.

J Oral Maxillofac Surg 66:1390-1398.

5. Ziober BL, Silverman SS Jr, Kramer RH. (2001) Adhesive mechanisms regulating invasion and

metastasis in oral cancer. Crit Rev Oral Biol Med 12:499-510. 
6. Bánkfalvi A, Krassort M, Buchwalow IB, et al. (2002) Gains and losses of adhesion molecules (CD44,

E-cadherin, and beta-catenin) during oral carcinogenesis and tumour progression. J Pathol

198:343-351.

7. Arora S, Kaur J, Sharma C, et al. (2005) Stromelysin 3, Ets-1, and vascular endothelial growth factor expression in oral precancerous and cancerous lesions: correlation with microvessel density,

progression, and prognosis. Clin Cancer Res 15;11:2272-2284.

8. Yanamoto S, Kawasaki G, Yoshitomi I, et al. (2007) Clinicopathologic significance of EpCAM expression in squamous cell carcinoma of the tongue and its possibility as a potential target for tongue cancer gene therapy. Oral Oncol 43:869-877.

9. Lin M, Smith LT, Smiraglia DJ, et al. (2006) DNA copy number gains in head and neck squamous cell carcinoma. Oncogene. ;25:1424-1433.

10. Hui AB, Or YY, Takano H, et al. (2005) Array-based comparative genomic hybridization analysis 
identified cyclin D1 as a target oncogene at 11q13.3 in nasopharyngeal carcinoma. Cancer Res.

65:8125-8133.

11. Zaharieva BM, Simon R, Diener PA, et al. (2003) High-throughput tissue microarray analysis of

11 q13 gene amplification (CCND1, FGF3, FGF4, EMS1) in urinary bladder cancer. J Pathol.

201:603-608

12. Meredith SD, Levine PA, Burns JA, et al. (1995) Chromosome 11q13 amplification in head and neck

squamous cell carcinoma. Association with poor prognosis. Arch Otolaryngol Head Neck Surg.

121:790-794.

13. Schuuring E. (1995) The involvement of the chromosome 11q13 region in human malignancies: cyclin

D1 and EMS1 are two new candidate oncogenes--a review. Gene. 159:83-96.

14. Merritt WD, Weissler MC, Turk BF, et al. (1990) Oncogene amplification in squamous cell carcinoma of the head and neck. Arch Otolaryngol Head Neck Surg. 116:1394-1398. 
15. Leonard JH, Kearsley JH, Chenevix-Trench G,et al. (1991) Analysis of gene amplification in head-and-neck squamous-cell carcinoma. Int J Cancer. 48:511-515.

16. Williams ME, Gaffey MJ, Weiss LM, et al. (1993) Chromosome 11Q13 amplification in head and neck squamous cell carcinoma. Arch Otolaryngol Head Neck Surg. 119:1238-1243.

17. Callender T, el-Naggar AK, Lee MS, et al. (1994) PRAD-1 (CCND1)/cyclin D1 oncogene amplification in primary head and neck squamous cell carcinoma. Cancer. 74:152-158.

18. Fortin A, Guerry M, Guerry R, et al. (1997) Chromosome 11q13 gene amplifications in oral and oropharyngeal carcinomas: no correlation with subclinical lymph node invasion and disease recurrence.

Clin Cancer Res. 3:1609-1614.

19. Akervall JA, Michalides RJ, Mineta H, et al. (1997) Amplification of cyclin D1 in squamous cell carcinoma of the head and neck and the prognostic value of chromosomal abnormalities and cyclin D1 overexpression. Cancer. 79:380-389. 
20. Alavi S, Namazie A, Calcaterra TC, et al. (1999) Clinical application of fluorescence in situ

hybridization for chromosome 11q13 analysis in head and neck cancer. Laryngoscope. 109:874-879.

21. Rodrigo JP, García LA, Ramos S, et al. (2000) EMS1 gene amplification correlates with poor

prognosis in squamous cell carcinomas of the head and neck. Clin Cancer Res. 6:3177-3182.

22. Xia J, Chen Q, Li B, et al. (2007) Amplifications of TAOS1 and EMS1 genes in oral carcinogenesis:

association with clinicopathological features. Oral Oncol. 43:508-514.

23. Freier K, Sticht C, Hofele C, et al. (2006) Recurrent coamplification of cytoskeleton-associated genes

EMS1 and SHANK2 with CCND1 in oral squamous cell carcinoma. Genes Chromosomes Cancer.

$45: 118-125$

24. Muller D, Millon R, Lidereau R, et al. (1994) Frequent amplification of 11q13 DNA markers is associated with lymph node involvement in human head and neck squamous cell carcinomas. Eur J Cancer B Oral Oncol. 30:113-120. 
25. Muller D, Millon R, Velten M, et al. (1997) Amplification of 11q13 DNA markers in head and neck squamous cell carcinomas: correlation with clinical outcome. Eur J Cancer. 33:2203-2210.

26. Takes RP, Baatenburg de Jong RJ, Schuuring E, et al. (1997) Markers for assessment of nodal metastasis in laryngeal carcinoma. Arch Otolaryngol Head Neck Surg. 123:412-419.

27. Rodrigo JP, García LA, Ramos S, et al. (2000) EMS1 gene amplification correlates with poor prognosis in squamous cell carcinomas of the head and neck. Clin Cancer Res. 6:3177-3182.

28. Schuuring E, Verhoeven E, Mooi WJ, et al. (1992) Identification and cloning of two overexpressed genes, U21B31/PRAD1 and EMS1, within the amplified chromosome 11q13 region in human carcinomas. Oncogene. 7:355-361.

29. Fantl V, Smith R, Brookes S, et al. (1993) Chromosome 11q13 abnormalities in human breast cancer. Cancer Surv. 18:77-94.

30. Karlseder J, Zeillinger R, Schneeberger C, et al. (1994) Patterns of DNA amplification at band q13 of 
chromosome 11 in human breast cancer. Genes Chromosomes Cancer. 9:42-48.

31. Peters G, Fantl V, Smith R, et al. (1995) Chromosome 11q13 markers and D-type cyclins in breast cancer. Breast Cancer Res Treat. 33:125-135.

32. Weed SA, Parsons JT. (2001) Cortactin: coupling membrane dynamics to cortical actin assembly.

Oncogene. 20:6418-6434.

33. Daly RJ. (2004) Cortactin signalling and dynamic actin networks. Biochem J. 382:13-25.

34. Xiao-Ping H, Tie-Hua R, Peng L, et al. (2006) Cyclin D1 overexpression in esophageal cancer from southern China and its clinical significance. Cancer Lett. 231:94-101.

35. Bringuier PP, Tamimi Y, Schuuring E, et al. (1996) Expression of cyclin D1 and EMS1 in bladder tumours; relationship with chromosome 11q13 amplification. Oncogene. 12:1747-1753.

36. Rothschild BL, Shim AH, Ammer AG, et al. (2006) Cortactin overexpression regulates actin-related protein $2 / 3$ complex activity, motility, and invasion in carcinomas with chromosome $11 \mathrm{q} 13$ 
amplification. Cancer Res. 66:8017-8025.

37. Luo ML, Shen XM, Zhang Y, et al. (2006) Amplification and overexpression of CTTN (EMS1)

contribute to the metastasis of esophageal squamous cell carcinoma by promoting cell migration and anoikis resistance. Cancer Res. 66:11690-11699.

38. Hsu NY, Yeh KT, Chiang IP, et al. (2008) Cortactin overexpression in the esophageal squamous cell carcinoma and its involvement in the carcinogenesis. Dis Esophagus. 21:402-408.

39. Strewler GJ, Nissenson RA. (1990) Hypercalcemia in malignancy. West J Med. 153:635-640.

40. Strewler GJ. (2000) The physiology of parathyroid hormone-related protein. N Engl J Med. $342: 177-185$.

41. Yamada T, Tsuda M, Ohba Y, et al. (2008) PTHrP promotes malignancy of human oral cancer cell downstream of the EGFR signaling. Biochem Biophys Res Commun. 368:575-581.

42 Lua BL, Low BC. (2005) Cortactin phosphorylation as a switch for actin cytoskeletal network and cell 
dynamics control. FEBS Lett. 579:577-585.

43 Patel AS, Schechter GL, Wasilenko WJ,et al. (1998) Overexpression of EMS1/cortactin in NIH3T3

fibroblasts causes increased cell motility and invasion in vitro. Oncogene. 16:3227-3232.

44 Li Y, Tondravi M, Liu J, et al. (2001) Cortactin potentiates bone metastasis of breast cancer cells.

Cancer Res. 61:6906-6911.

45 Coopman PJ, Do MT, Thompson EW, et al. (1998) Phagocytosis of cross-linked gelatin matrix by

human breast carcinoma cells correlates with their invasive capacity. Clin Cancer Res. 4:507-515.

46. Chen WT. (1989) Proteolytic activity of specialized surface protrusions formed at rosette contact sites

of transformed cells. J Exp Zool. 251:167-185.

47. Wu H, Parsons JT. (1993) Cortactin, an 80/85-kilodalton pp60src substrate, is a filamentous

actin-binding protein enriched in the cell cortex. J Cell Biol. 120:1417-1426.

48. Helwani FM, Kovacs EM, Paterson AD, et al. (2004) Cortactin is necessary for E-cadherin-mediated 
contact formation and actin reorganization. J Cell Biol. 164:899-910.

49. Kovacs EM, Goodwin M, Ali RG, et al. (2002) Cadherin-directed actin assembly: E-cadherin

physically associates with the Arp2/3 complex to direct actin assembly in nascent adhesive contacts.

Curr Biol. 12:379-382.

50. Weed SA, Karginov AV, Schafer DA, et al. (2000) Cortactin localization to sites of actin assembly in lamellipodia requires interactions with F-actin and the Arp2/3 complex. J Cell Biol. 151:29-40.

51. Weaver AM, Karginov AV, Kinley AW, et al. (2001) Cortactin promotes and stabilizes Arp2/3-induced actin filament network formation. Curr Biol. 11:370-374.

52. El Sayegh TY, Arora PD, Laschinger CA, et al. (2004) Cortactin associates with N-cadherin adhesions and mediates intercellular adhesion strengthening in fibroblasts. J Cell Sci. 117:5117-5131.

53. Hoschuetzky H, Aberle H, Kemler R. (1994) Beta-catenin mediates the interaction of the cadherin-catenin complex with epidermal growth factor receptor. J Cell Biol. 127:1375-1380. 
54. Balzar M, Prins FA, Bakker HA, et al. (1994) The structural analysis of adhesions mediated by

Ep-CAM. Exp Cell Res. 246:108-121.

55. Winter MJ, Nagelkerken B, Mertens AE,et al. (2003) Expression of Ep-CAM shifts the state of cadherin-mediated adhesions from strong to weak. Exp Cell Res. 285:50-58.

56. Todd R, Wong DT. (1999) Epidermal growth factor receptor (EGFR) biology and human oral cancer.

Histol Histopathol. 14:491-500.

57. Rubin Grandis J, Melhem MF, Gooding WE, et al. (1998) Levels of TGF-alpha and EGFR protein in head and neck squamous cell carcinoma and patient survival. J Natl Cancer Inst.90:824-832.

58. Timpson P, Lynch DK, Schramek D, et al. (2005) Cortactin overexpression inhibits ligand-induced down-regulation of the epidermal growth factor receptor. Cancer Res. 65:3273-3280.

59. Burtis WJ, Brady TG, Orloff JJ, et al. (1990) Immunochemical characterization of circulating parathyroid hormone-related protein in patients with humoral hypercalcemia of cancer. N Engl J Med. 
322:1106-1112.

60. Liao J, McCauley LK. (2006) Skeletal metastasis: Established and emerging roles of parathyroid hormone related protein (PTHrP). Cancer Metastasis Rev. 25:559-571.

61. Tuschl T. (2002) Expanding small RNA interference. Nat Biotechnol. 20:446-448.

62. Kudo Y, Kitajima S, Ogawa I, et al. (2005) Small interfering RNA targeting of S phase

kinase-interacting protein 2 inhibits cell growth of oral cancer cells by inhibiting p27 degradation. Mol Cancer Ther. 4:471-476.

63. Yanamoto S, Iwamoto T, Kawasaki G, et al. (2005) Silencing of the p53R2 gene by RNA interference inhibits growth and enhances 5-fluorouracil sensitivity of oral cancer cells. Cancer Lett. 223:67-76. 


\section{Figure Legends}

Figure 1

Representative immunohistochemical staining for cortactin. (A) Negative staining without cortactin

overexpression is shown in normal oral epithelium (40×). (B) Well-differentiated squamous cell carcinoma

demonstrating strong cortactin expression (staining index of 3 ) and diffuse invasion (40×). (C)

Immunohistochemical staining for cortactin demonstrates strong cytoplasmic expression in the cancer nests

$(200 \times)$. (D) Cortactin overexpression (intense staining) is shown in squamous cell carcinoma cells at the

invasive front of the tumor $(200 \times)$.

Figure 2

(A) Representative RT-PCR for the suppression of cortactin in SAS cells. Cells were transfected with scrambled siRNA (control) or cortactin siRNA. After $72 \mathrm{~h}$, isolated total RNA was analyzed using RT-PCR. 
(B) Western blot analysis for the suppression of cortactin in SA cells. Western blot analyses show cortactin and $\beta$-actin expression in the whole cell lysate proteins. (C) The graph shows a significant decrease of the invasion index in SAS cells treated with cortactin siRNA $(\mathrm{P}<0.01)$.

Figure 3

(A) Representative RT-PCR for the suppression of cortactin in SAS cells. Cells were transfected with scrambled siRNA (control) or cortactin siRNA. After $72 \mathrm{~h}$, isolated total RNA was analyzed using RT-PCR. The siRNA of cortactin reduced the mRNA expression levels of E-cadherin, $\beta$-catenin, EpCAM, FGFR, and PTHrP. (B) Western blot analysis for the suppression of cortactin in SAS cells. Western blot analysis show the decreased expression of E-cadherin, EpCAM, and EGFR. 


\begin{tabular}{|c|c|c|c|}
\hline & cortact & ressiom & \\
\hline & $(-)$ & $(+)$ & p value \\
\hline Normal epithelium & 10 & 0 & \\
\hline Squamous cell carcinoma & 38 & 32 & $p<0.01$ \\
\hline Gender & 22 & 17 & $n=0689$ \\
\hline Female & 16 & 15 & 0.000 \\
\hline $60 \leqq$ & 10 & 11 & \\
\hline $60>$ & 28 & 21 & $p=0.404$ \\
\hline $\mathrm{T}$ classification $\mathrm{T} 1+\mathrm{T} 2$ & 33 & 13 & $p<0.001$ \\
\hline $\mathrm{T} 3+\mathrm{T} 4$ & 5 & 19 & \\
\hline $\mathrm{N}$ classification $\mathrm{N} 0$ & 34 & 21 & $\mathrm{p}<0.05$ \\
\hline $\mathrm{N} 1+\mathrm{N} 2$ & 4 & 11 & \\
\hline Differentiation Well & 32 & 28 & $n=0695$ \\
\hline Moderate/Poor & 6 & 4 & $0-0.000$ \\
\hline Pattern of invasion Grades $1 / 2$ & 32 & 10 & $p<0.001$ \\
\hline Grades3/4 & 6 & 22 & \\
\hline
\end{tabular}

Table 1 Correlation of cortactin overexpression and clinicopathologic features 


$\begin{array}{lccc}\text { Parameter } & \text { Hazard ratio } & 95 \% \text { Cl } & P \text { value } \\ \text { T classification (T1+T2 versus T3+T4) } & 0.987 & -0.932-0.906 & 0.987 \\ \text { N classification (N0 versus N1+N2) } & 3.71 & 0.420-2.20 & 0.004 \\ \text { Differentiation (Well versus Moderate/Poor } & & -2.371-0.249 & 0.346 \\ \text { Pattern of invasion (Grades 1/2 versus Grades 3/4) } & 2.65 & & 0.038 \\ \text { Cortactin overexpression (- versus +) } & & 0.055-1.89 & 0.032\end{array}$

Table 2 Multivariate analysis (Cox regression) of different prognostic parameters 95\% CI, 95\% confidence interval. 

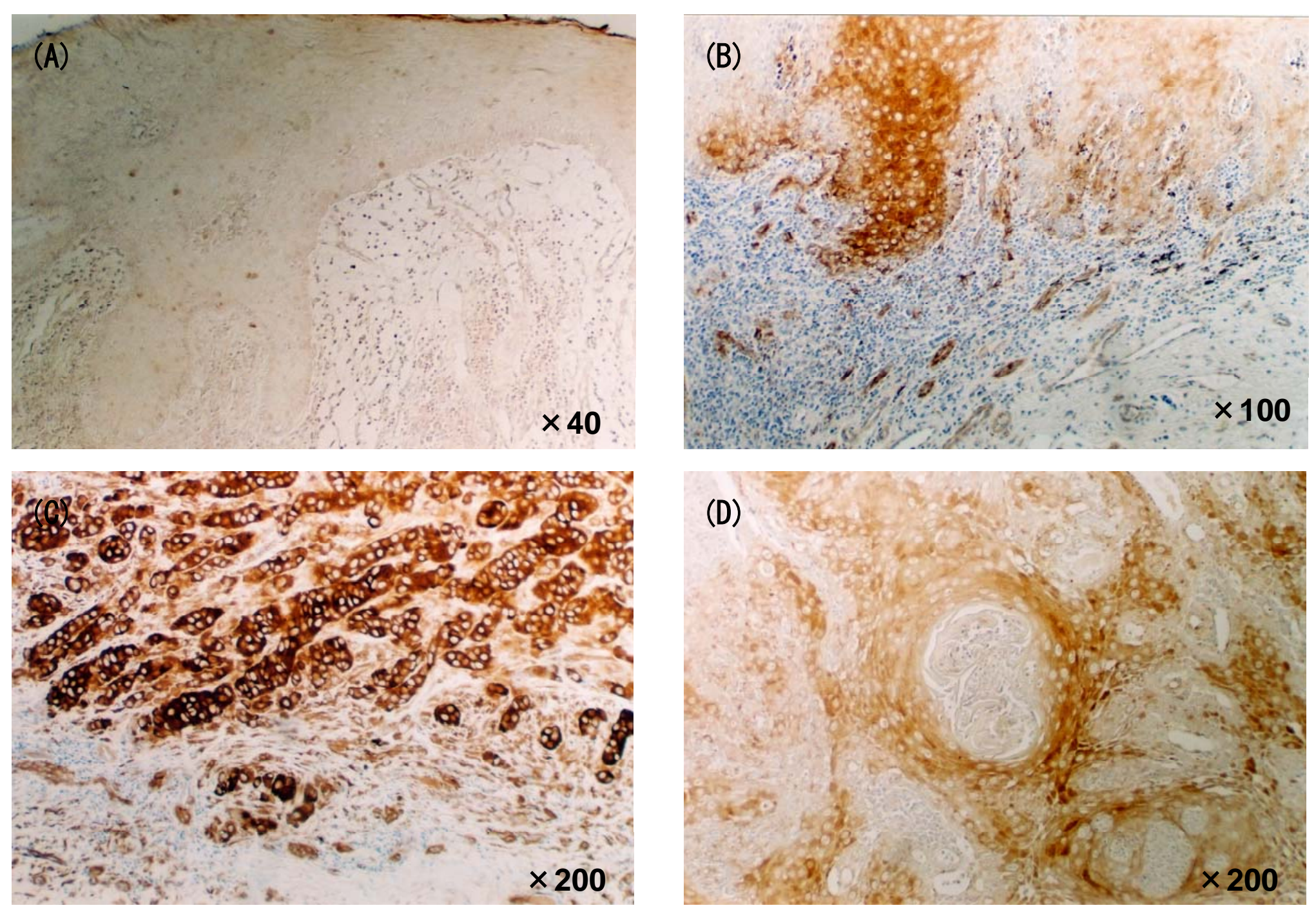

Fig. 1 


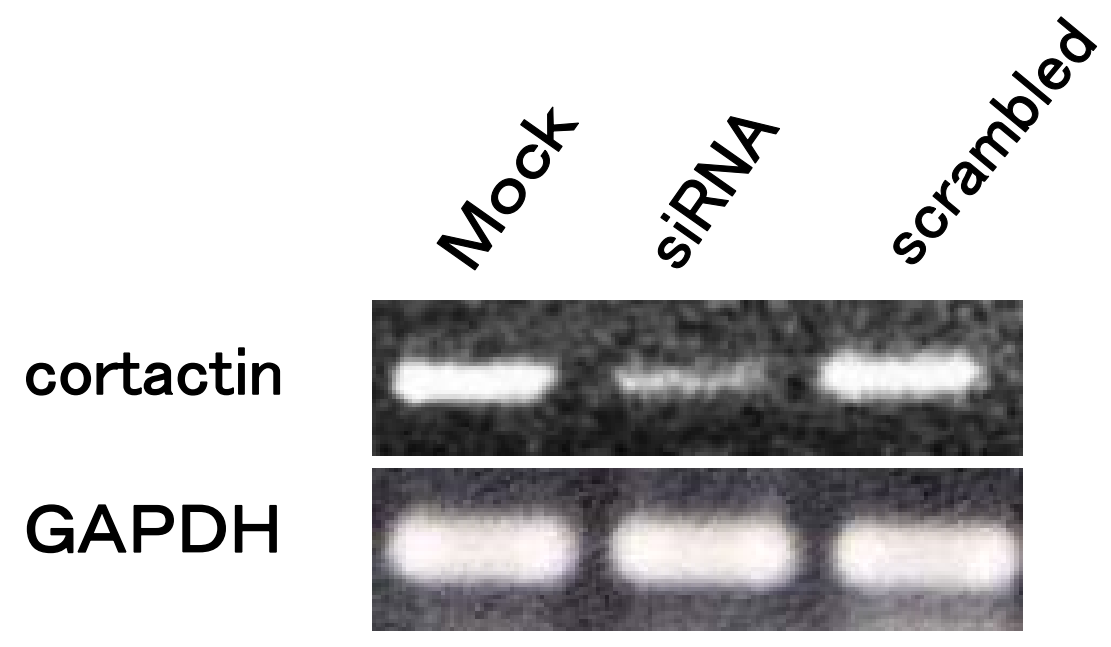

Fig. 2A 


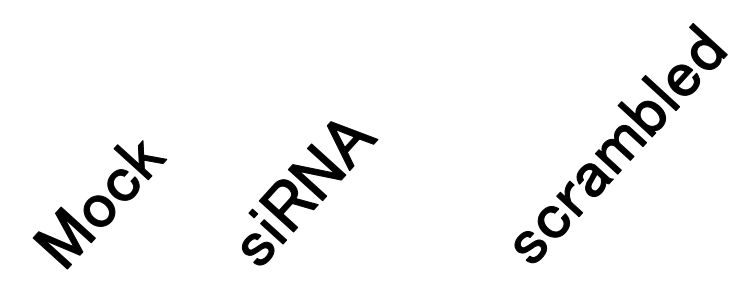

cortactin

$\beta$-actin

Fig. 2B 


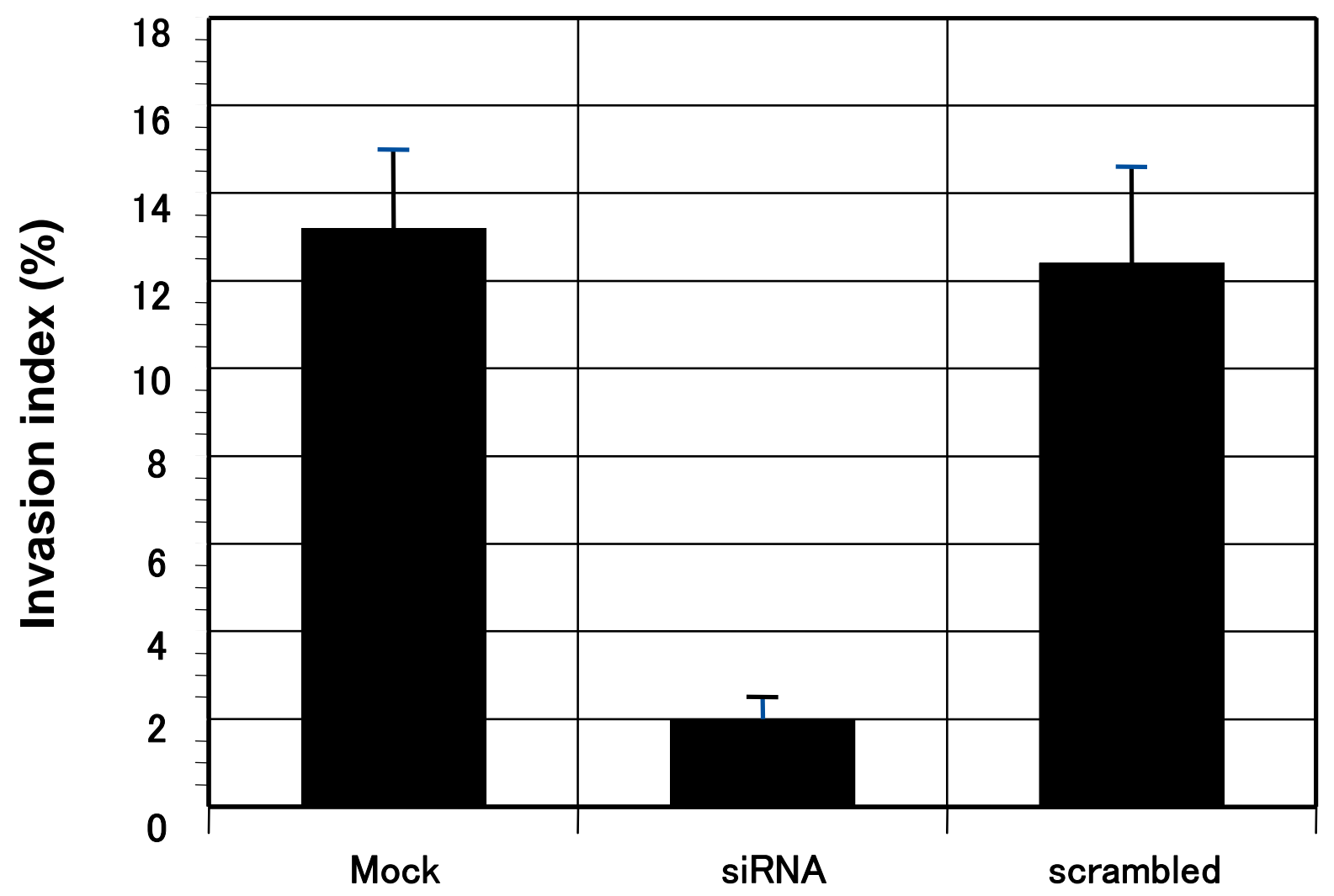

Fig. 2C 


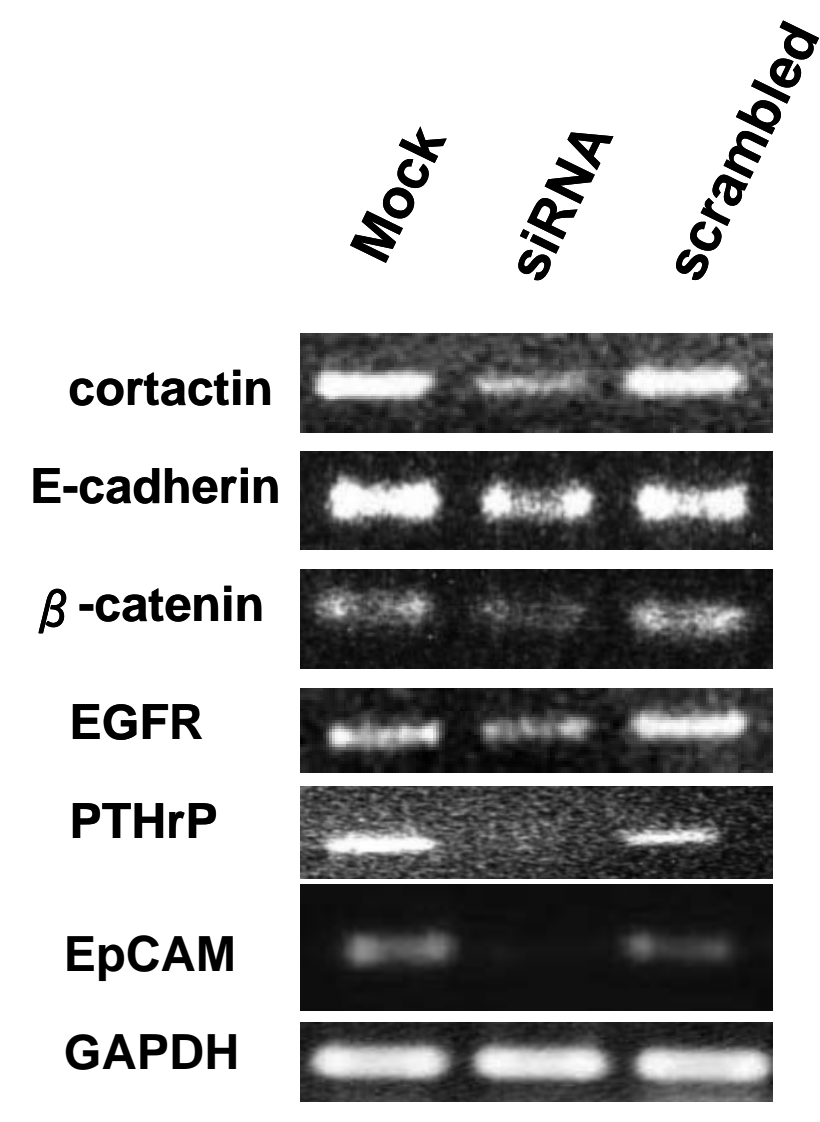

Fig. $3 A$ 


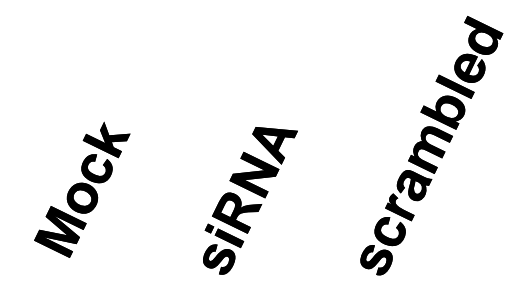

\section{cortactin \\ E-cadherin}

$\beta$-catenin

EGFR

EpCAM

$\beta$-actin

Fig. 3B 